\title{
Storage and Separation of Carbon Dioxide and Methane in Hydrated Covalent Organic Frameworks
}

J.M. Vicent-Luna, A. Luna-Triguero, and S. Calero*

Department of Physical, Chemical, and Natural Systems, Universidad Pablo de Olavide.

Ctra. Utrera km. 1. ES-41013 Seville, Spain.

*Email: scalero@upo.es 


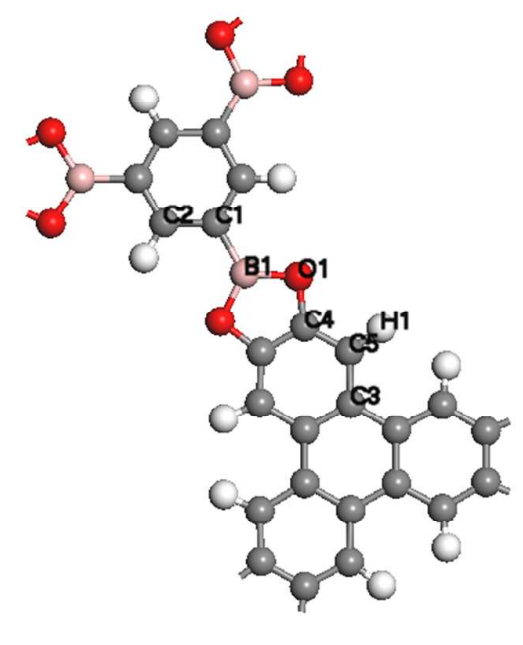

COF-6

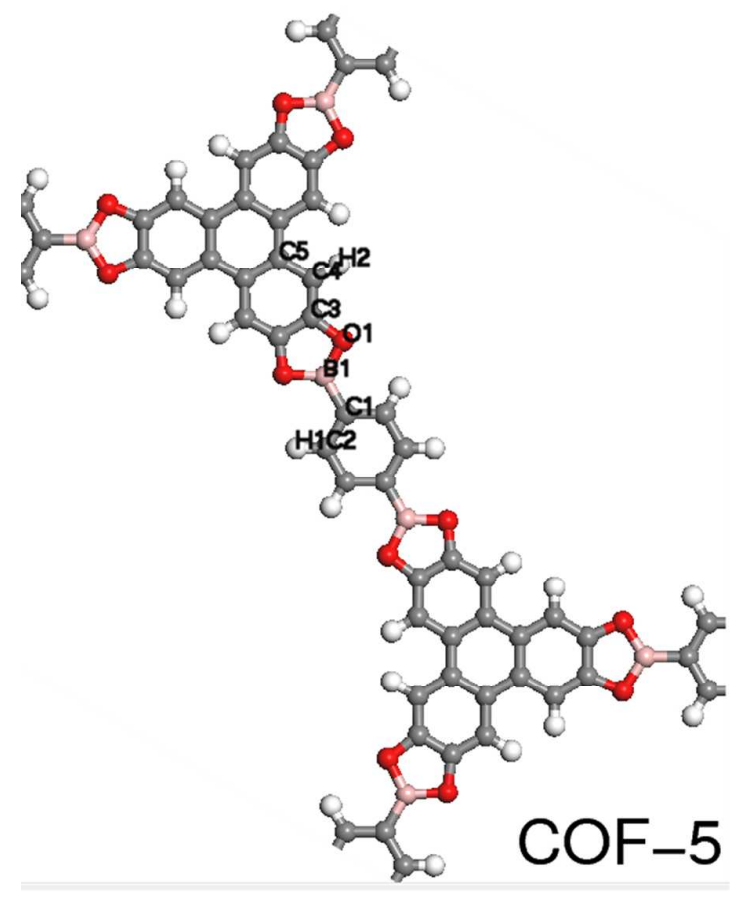

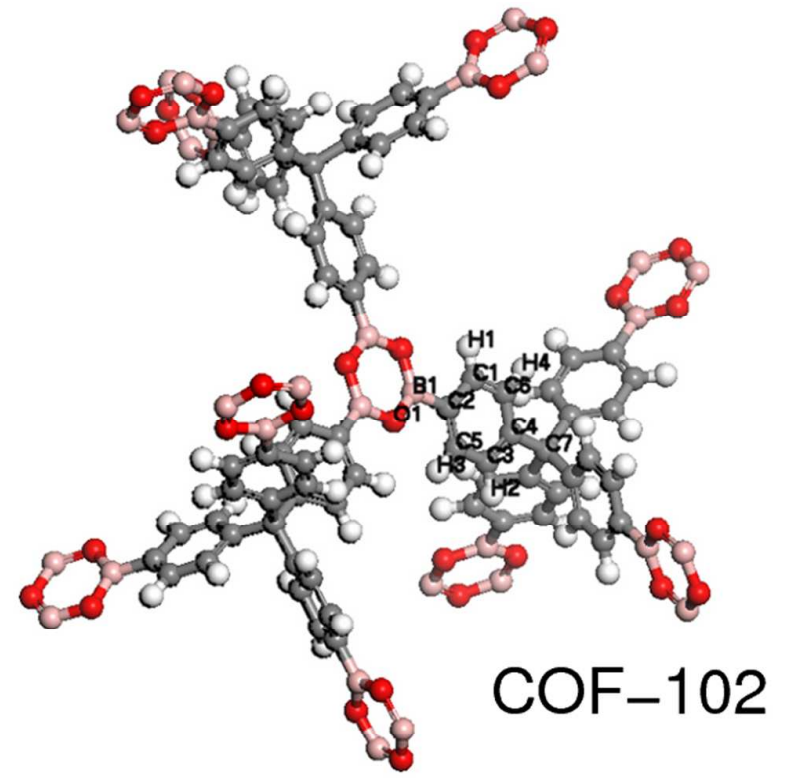

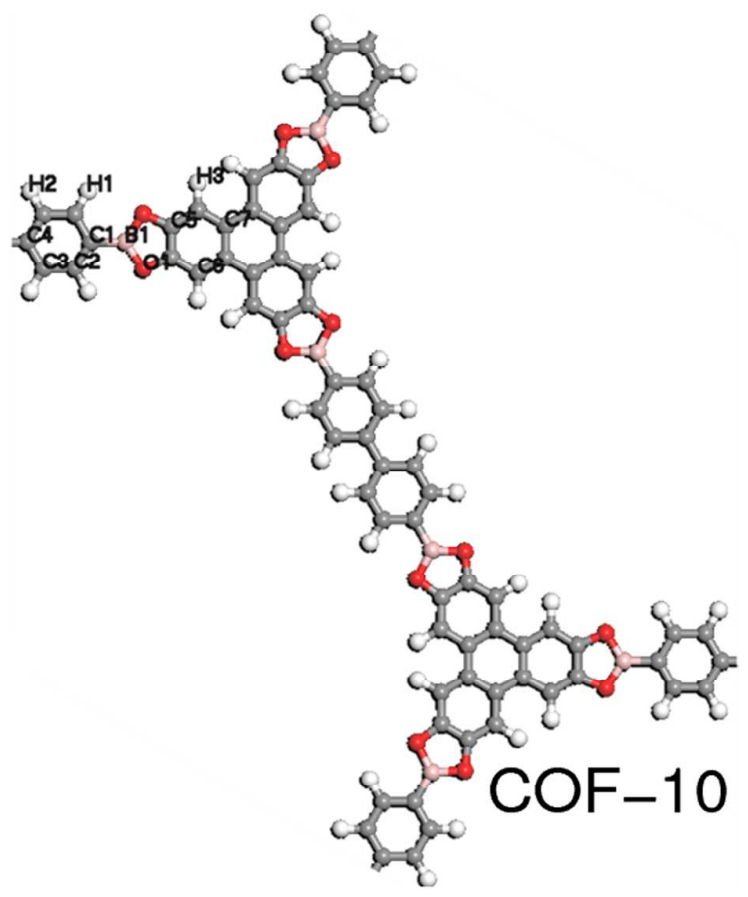

Figure S1. Schematic representation and atom labelling for COF-5, COF-6, COF-10, and COF-102. Hydrogen atoms in white, Boron atoms in pink, Oxygen atoms in red and Carbon atoms in grey. 

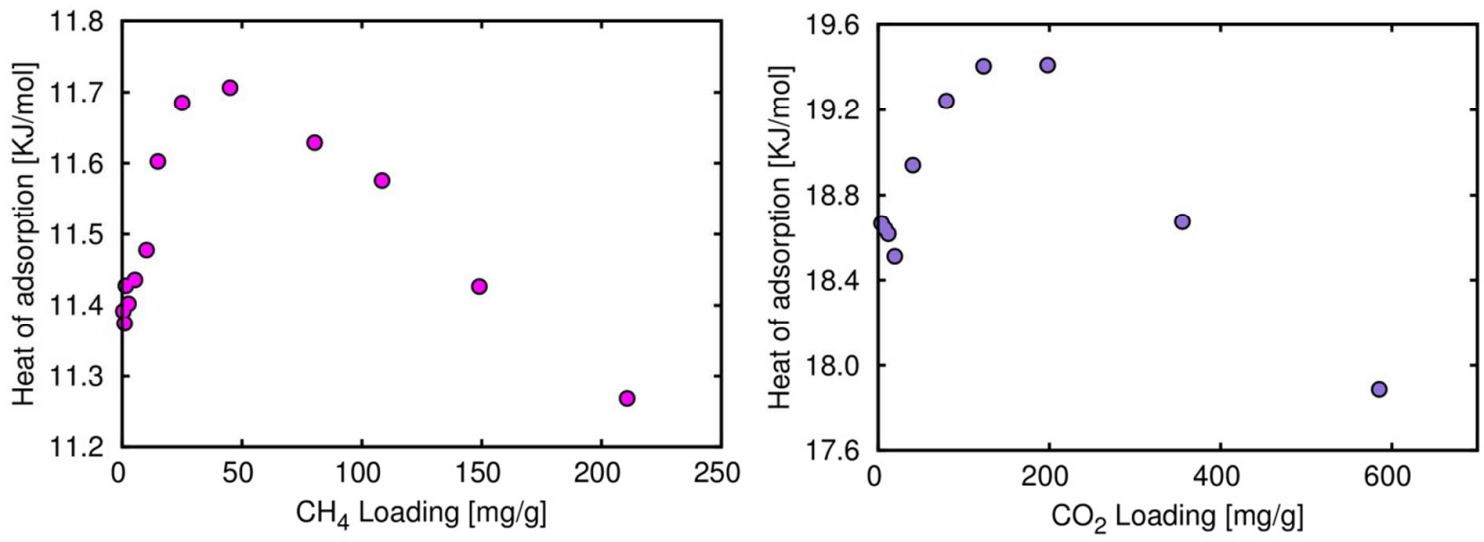

Figure S2. Heats of adsorption as a function of loading calculated for $\mathrm{CO}_{2}$ (purple) and $\mathrm{CH}_{4}$ (pink) in COF-5 at $298 \mathrm{~K}$.
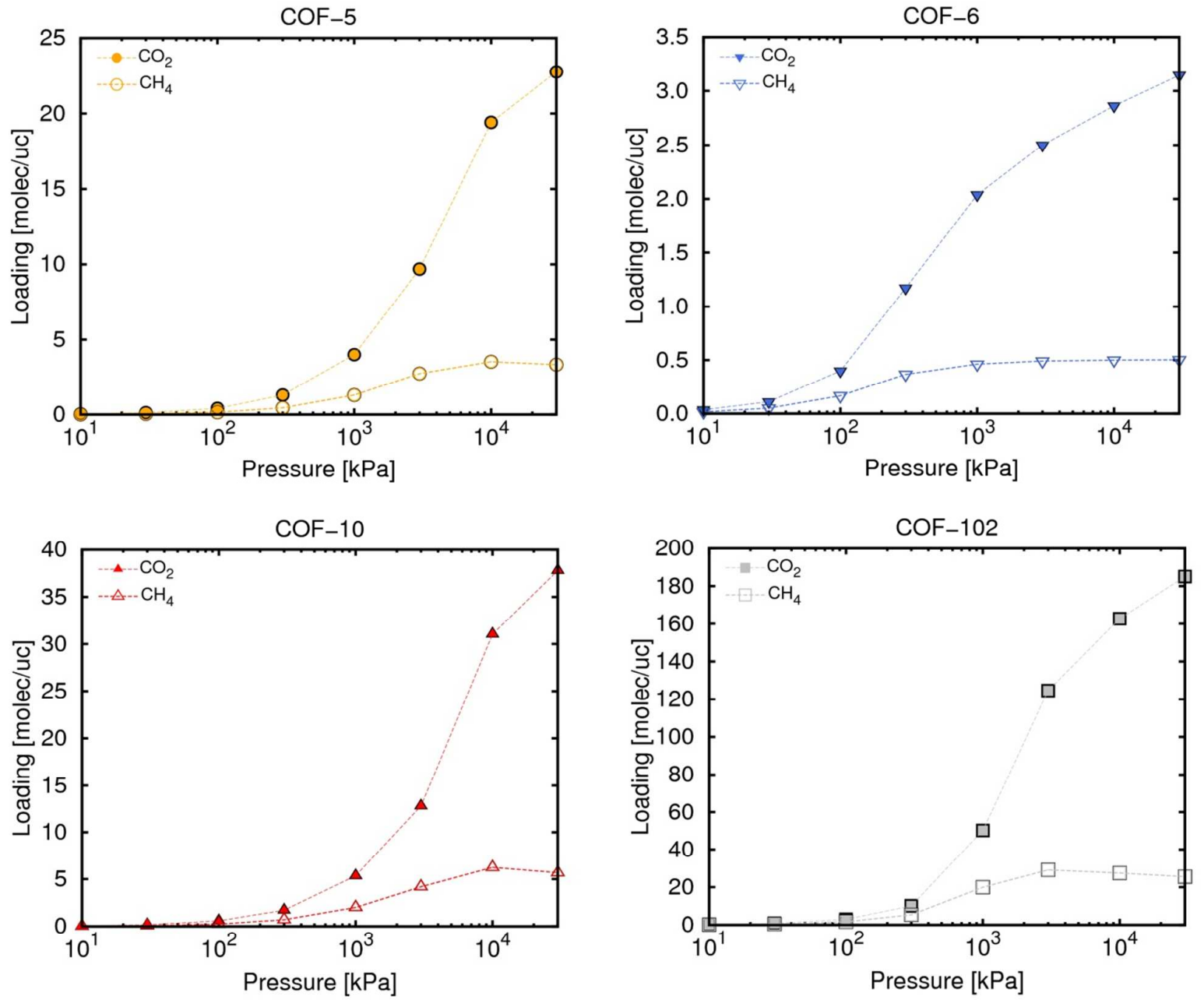

Figure S3. Adsorption isotherms calculated for the $\mathrm{CO}_{2} / \mathrm{CH}_{4}$ equimolar mixture at 298 $\mathrm{K}$ in COF-5, COF-6, COF-10, and COF-102. 


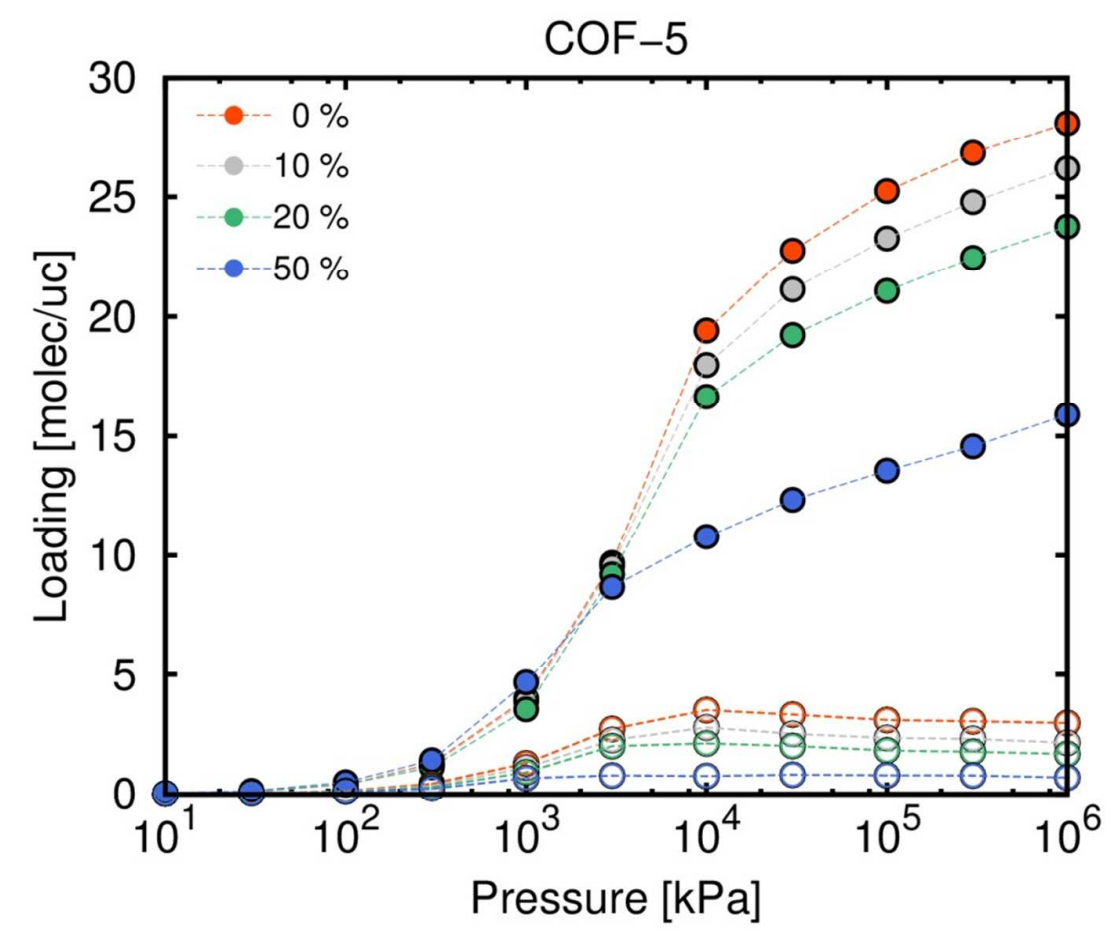

Figure S4. Adsorption isotherms calculated for the $\mathrm{CO}_{2} / \mathrm{CH}_{4}$ equimolar mixture in the dehydrated $(0 \%)$ and the hydrated $(10 \%, 20 \%$ and $50 \%)$ COF-5 at $298 \mathrm{~K} . \mathrm{CO}_{2}$ (full symbols) and $\mathrm{CH}_{4}$ (empty symbols).

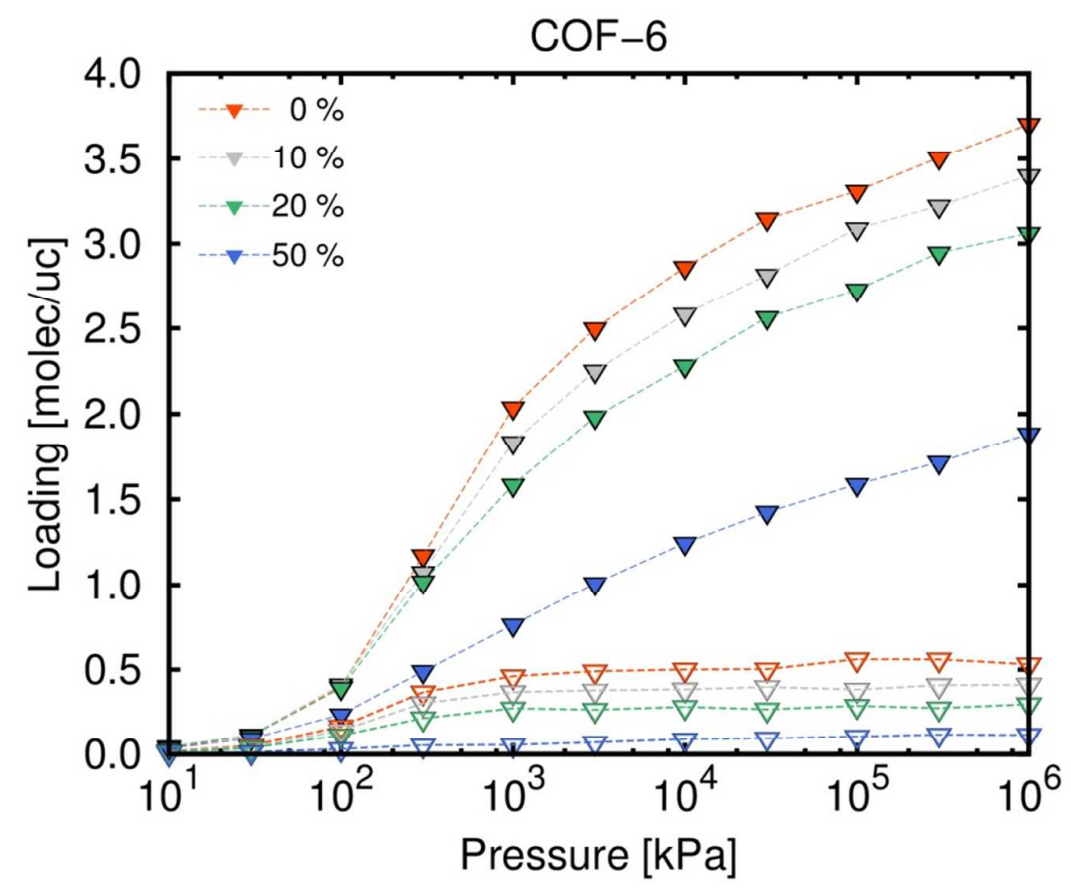

Figure S5. Adsorption isotherms calculated for the $\mathrm{CO}_{2} / \mathrm{CH}_{4}$ equimolar mixture in the dehydrated $(0 \%)$ and the hydrated $(10 \%, 20 \%$ and $50 \%)$ COF-6 at $298 \mathrm{~K} . \mathrm{CO}_{2}$ (full symbols) and $\mathrm{CH}_{4}$ (empty symbols). 


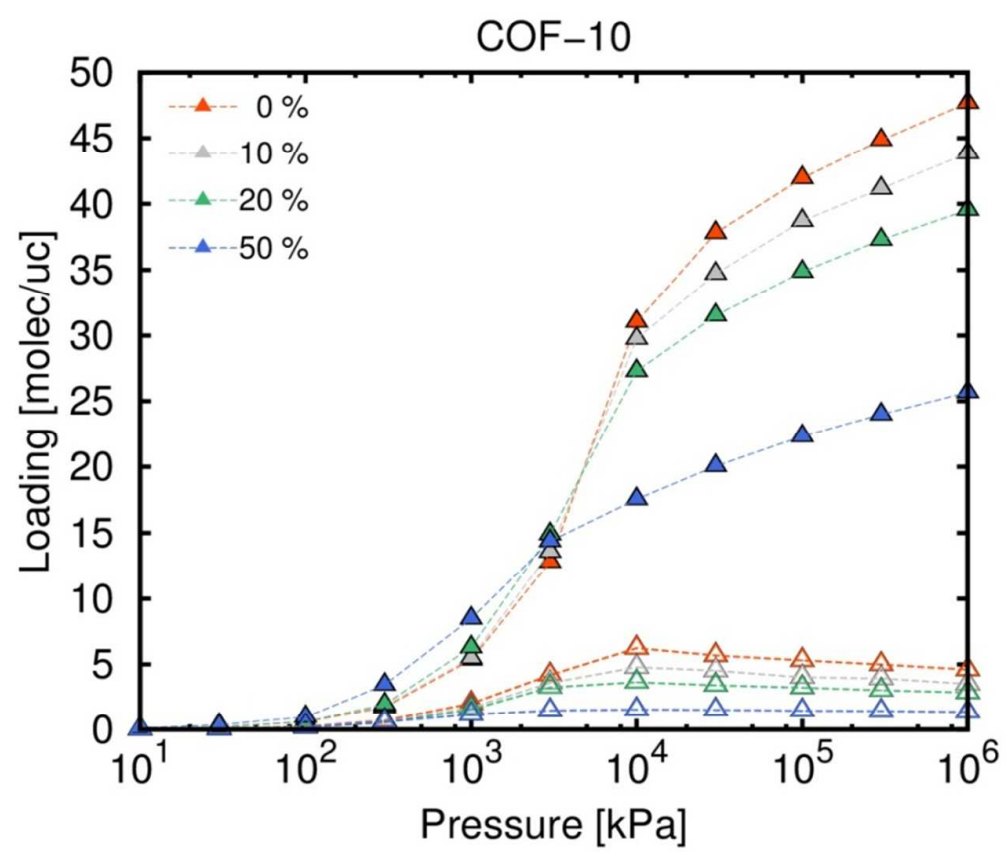

Figure S6. Adsorption isotherms calculated for the $\mathrm{CO}_{2} / \mathrm{CH}_{4}$ equimolar mixture in the dehydrated $(0 \%)$ and the hydrated $\left(10 \%, 20 \%\right.$ and 50\%) COF-10 at $298 \mathrm{~K} . \mathrm{CO}_{2}$ (full symbols) and $\mathrm{CH}_{4}$ (empty symbols).

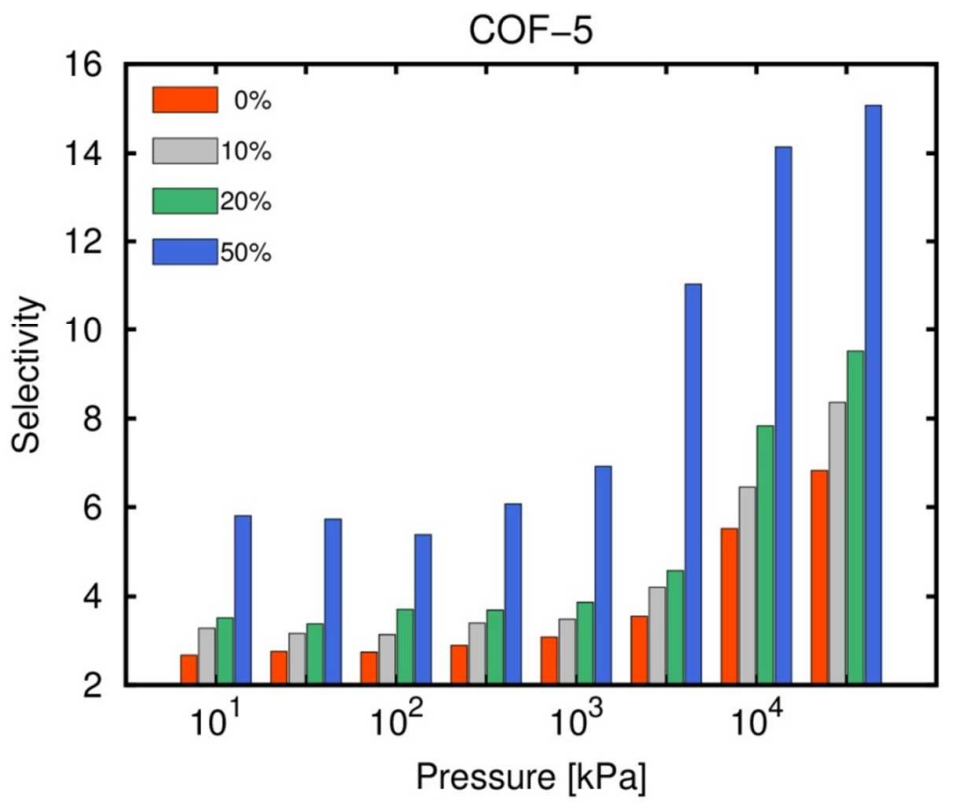

Figure S7. $\mathrm{CO}_{2} / \mathrm{CH}_{4}$ adsorption selectivity obtained from the adsorption isotherms of the equimolar mixture at $298 \mathrm{~K}$ in the dehydrated $(0 \%)$ and the hydrated $(10 \%, 20 \%$ and $50 \%)$ COF-5. 


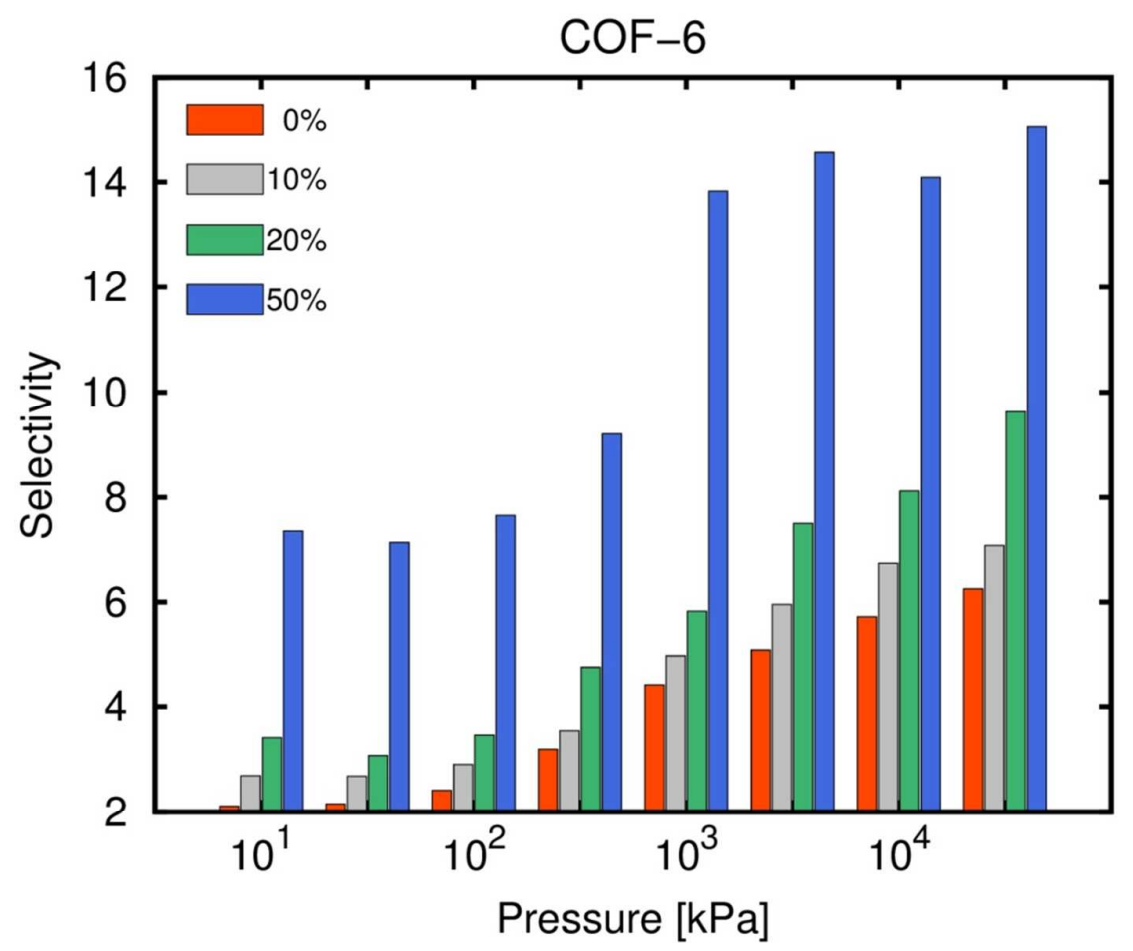

Figure S8. $\mathrm{CO}_{2} / \mathrm{CH}_{4}$ adsorption selectivity obtained from the adsorption isotherms of the equimolar mixture at $298 \mathrm{~K}$ in the dehydrated $(0 \%)$ and the hydrated $(10 \%, 20 \%$ and $50 \%)$ COF-6.

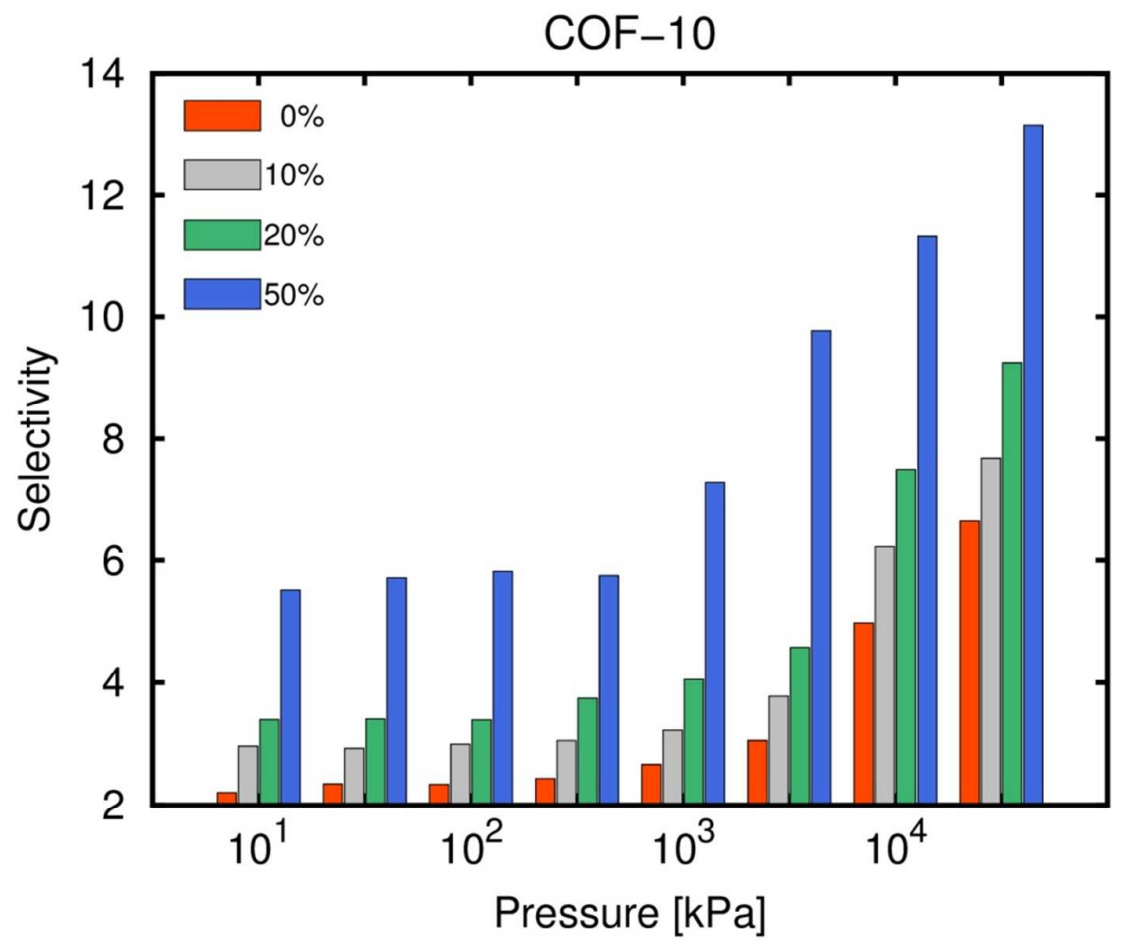

Figure S9. $\mathrm{CO}_{2} / \mathrm{CH}_{4}$ adsorption selectivity obtained from the adsorption isotherms of equimolar mixture at $298 \mathrm{~K}$ in the dehydrated $(0 \%)$ and the hydrated $(10 \%, 20 \%$ and $50 \%)$ COF- 10. 


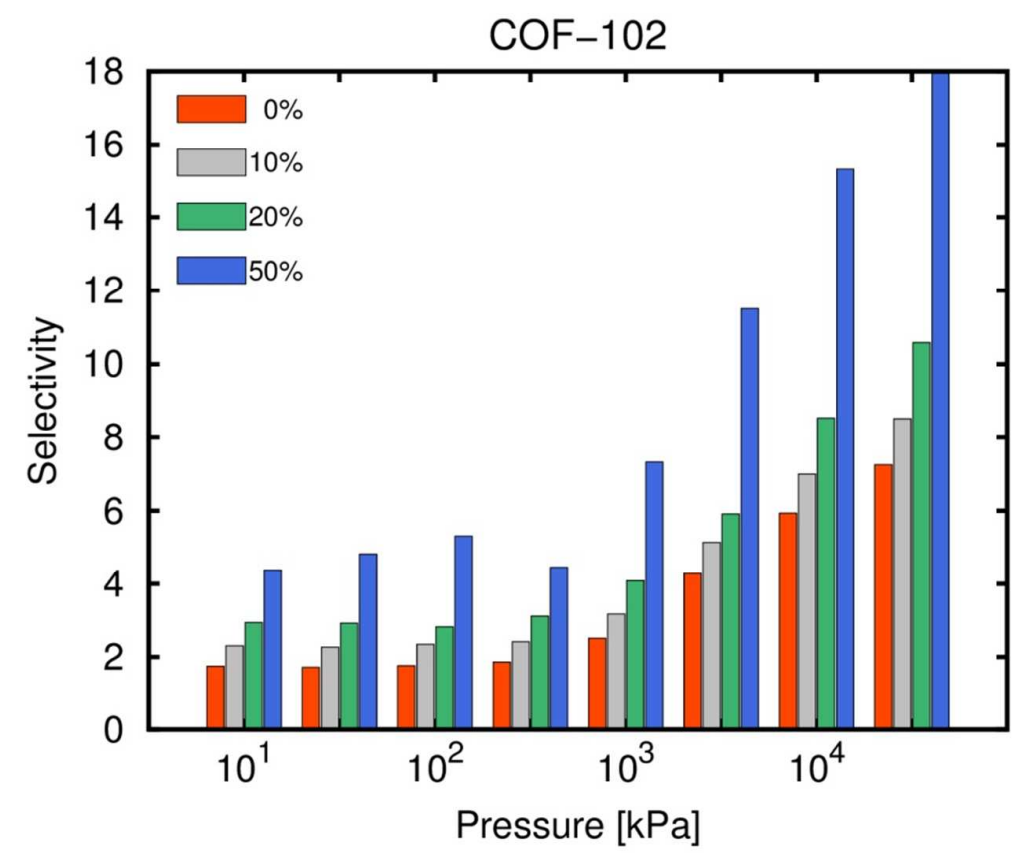

Figure S10. $\mathrm{CO}_{2} / \mathrm{CH}_{4}$ adsorption selectivity obtained from the adsorption isotherms of the equimolar mixture at $298 \mathrm{~K}$ in the dehydrated $(0 \%)$ and the hydrated $(10 \%, 20 \%$ and $50 \%)$ COF-102.

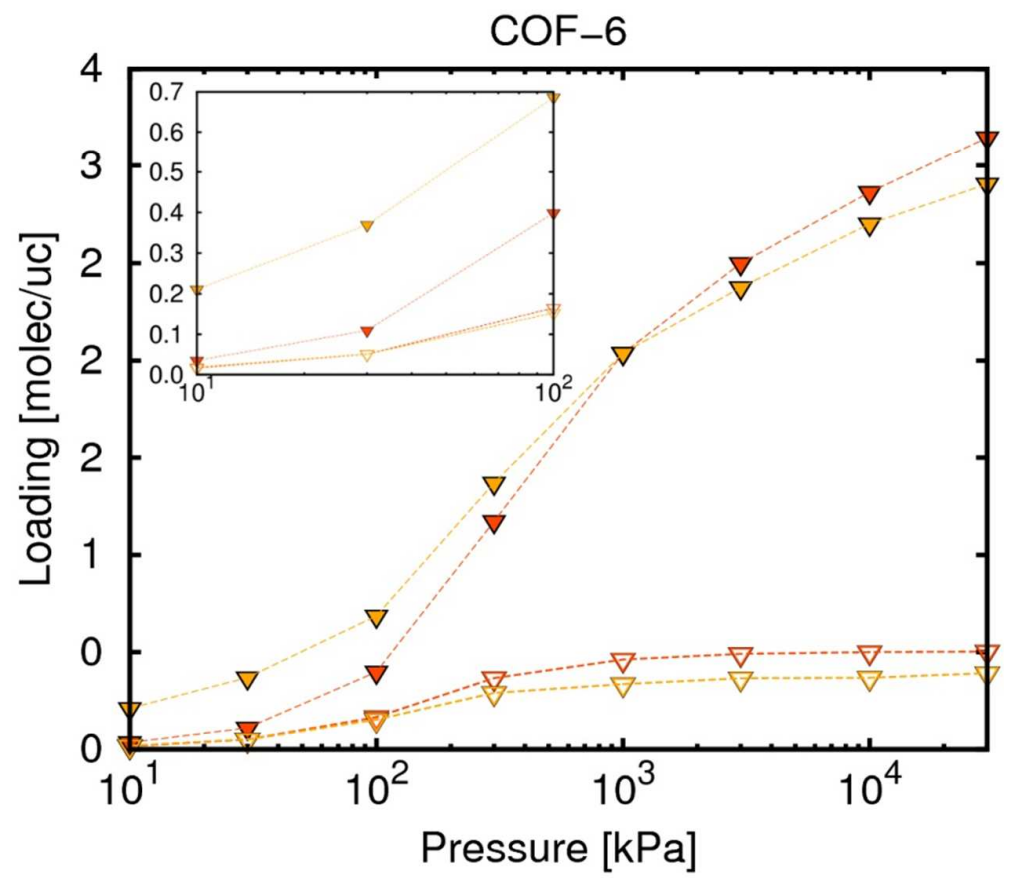

Figure S11. Adsorption isotherms calculated for the $\mathrm{CO}_{2} / \mathrm{CH}_{4}$ equimolar mixture at 298 $\mathrm{K}$ in COF-6 containing $10 \%$ of IL (yellow) and without IL (red). $\mathrm{CO}_{2}$ (full symbols) and $\mathrm{CH}_{4}$ (empty symbols). 


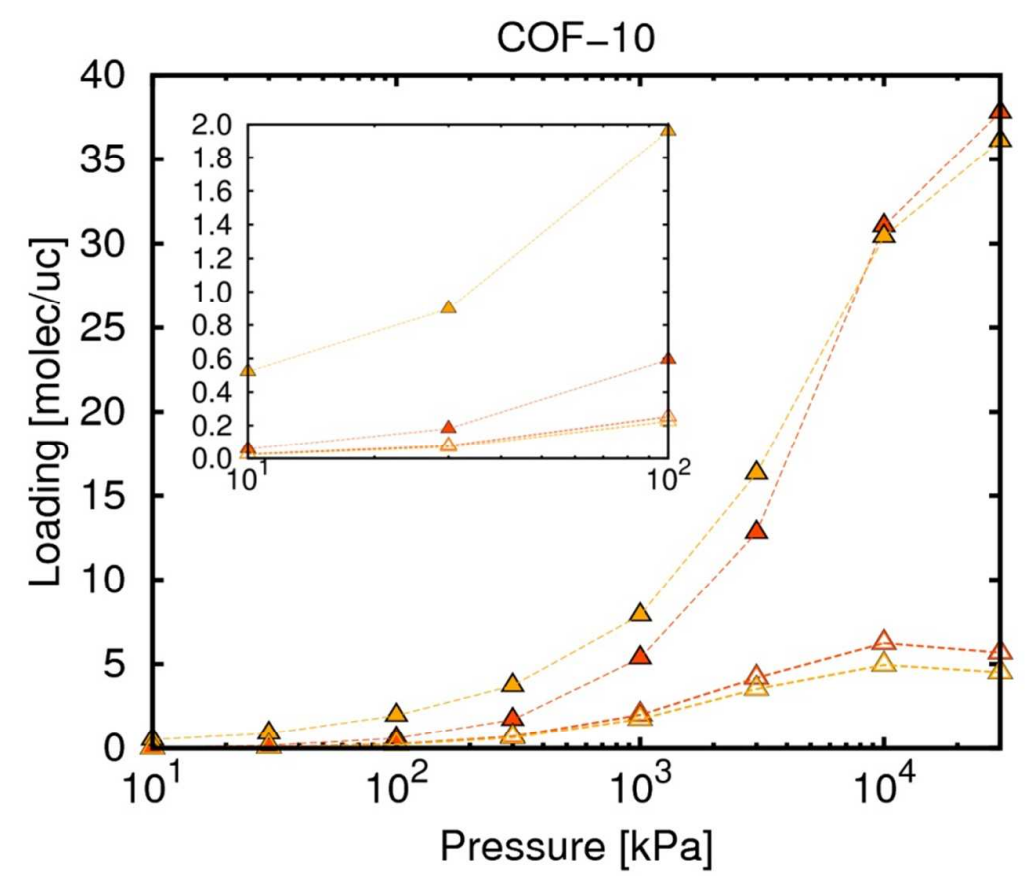

Figure S12. Adsorption isotherms calculated for the $\mathrm{CO}_{2} / \mathrm{CH}_{4}$ equimolar mixture at $298 \mathrm{~K}$ in COF-10 containing $10 \%$ of IL (yellow) and without IL (red). $\mathrm{CO}_{2}$ (full symbols) and $\mathrm{CH}_{4}$ (empty symbols).

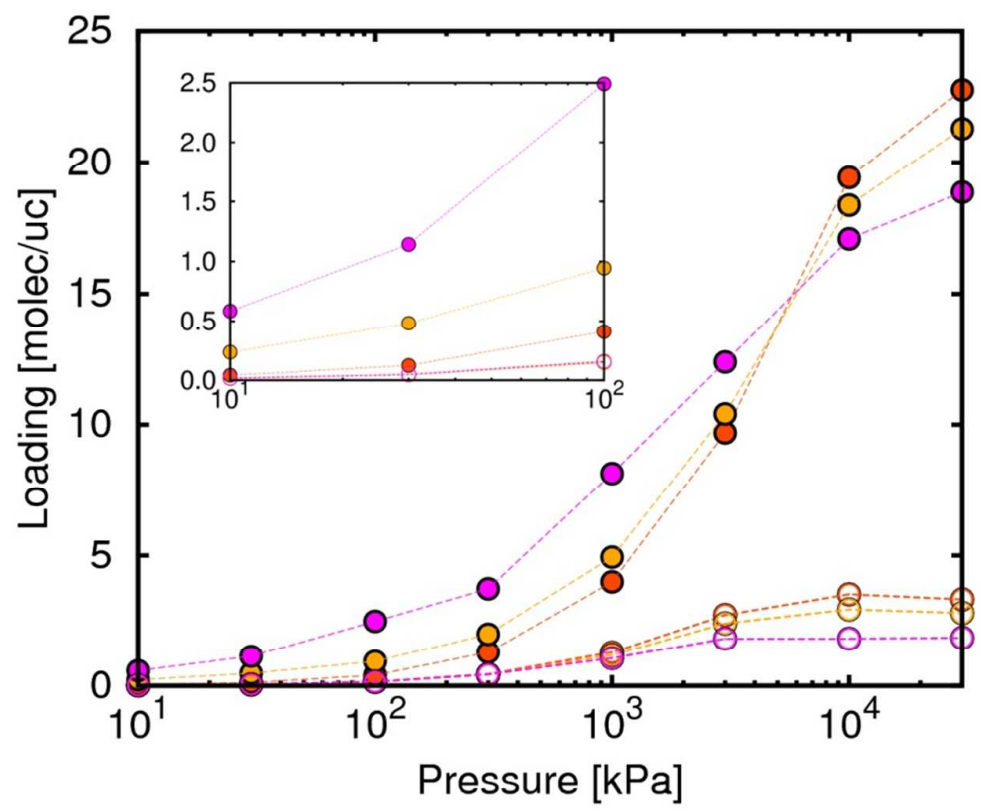

Figure S13. Adsorption isotherms calculated for the $\mathrm{CO}_{2} / \mathrm{CH}_{4}$ equimolar mixture at 298 $\mathrm{K}$ in COF-5 containing $10 \%$ of IL (yellow), $30 \%$ of IL (pink) and without IL (red). $\mathrm{CO}_{2}$ (full symbols) and $\mathrm{CH}_{4}$ (empty symbols). 


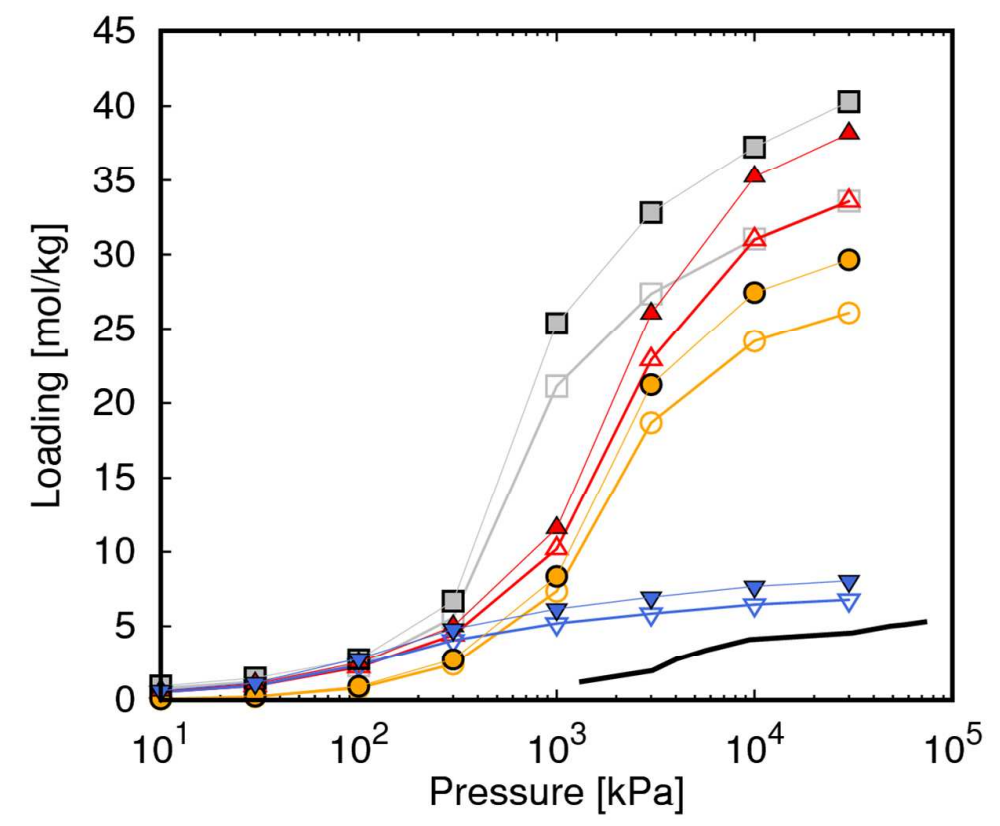

Figure S14. Adsorption isotherm of carbon dioxide in COF-5 (yellow circles), COF-6 (blue down triangles), COF-10 (red up triangles), and COF-102 (grey squares) containing $10 \%$ of IL. Open symbols represent data that do not take into account the weight of the solvent, closed symbols represent data that take into account the weight of the solvent. The black line is the experimental absorption isotherm of carbon dioxide in neat $[\mathrm{EMIM}]^{+}[\mathrm{SCN}]^{-}$IL (Taken from the solubility given in ref. 1).

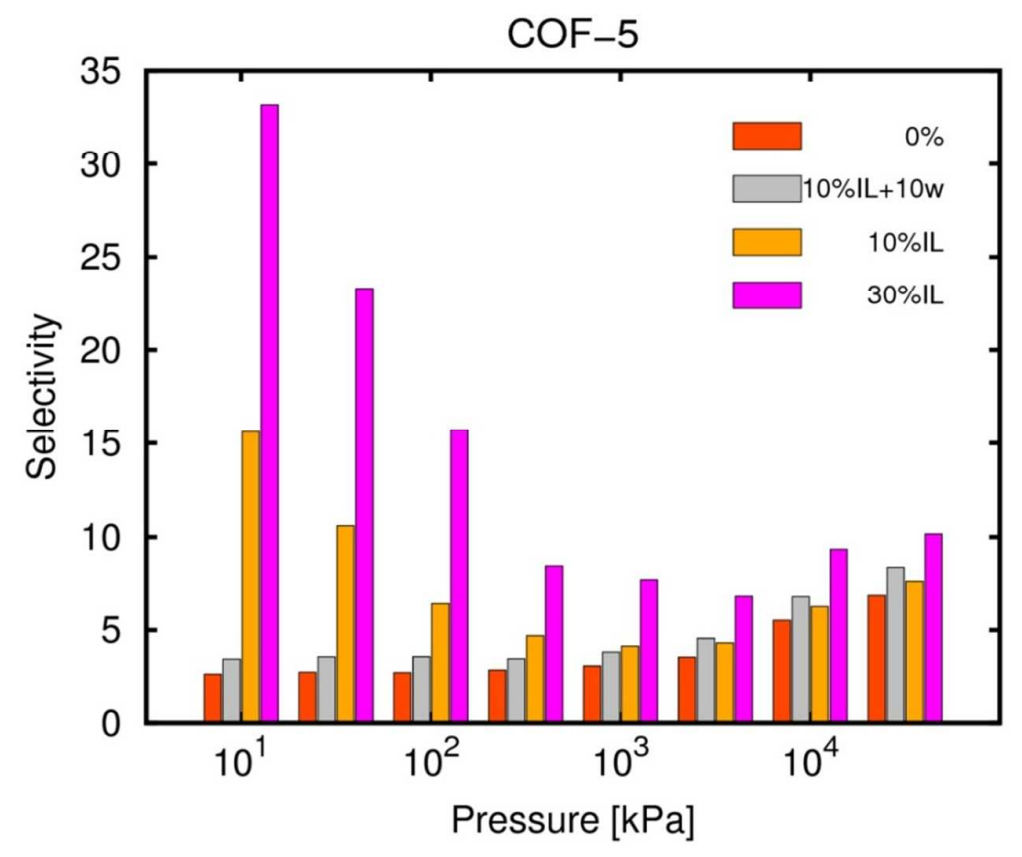


Figure S15. $\mathrm{CO}_{2} / \mathrm{CH}_{4}$ adsorption selectivity calculated from the adsorption isotherm of the equimolar mixture in COF-5 (0\%), COF-5 with IL (10\%-30\%), and COF-5 with $10 \%$ IL and $10 \%$ water.

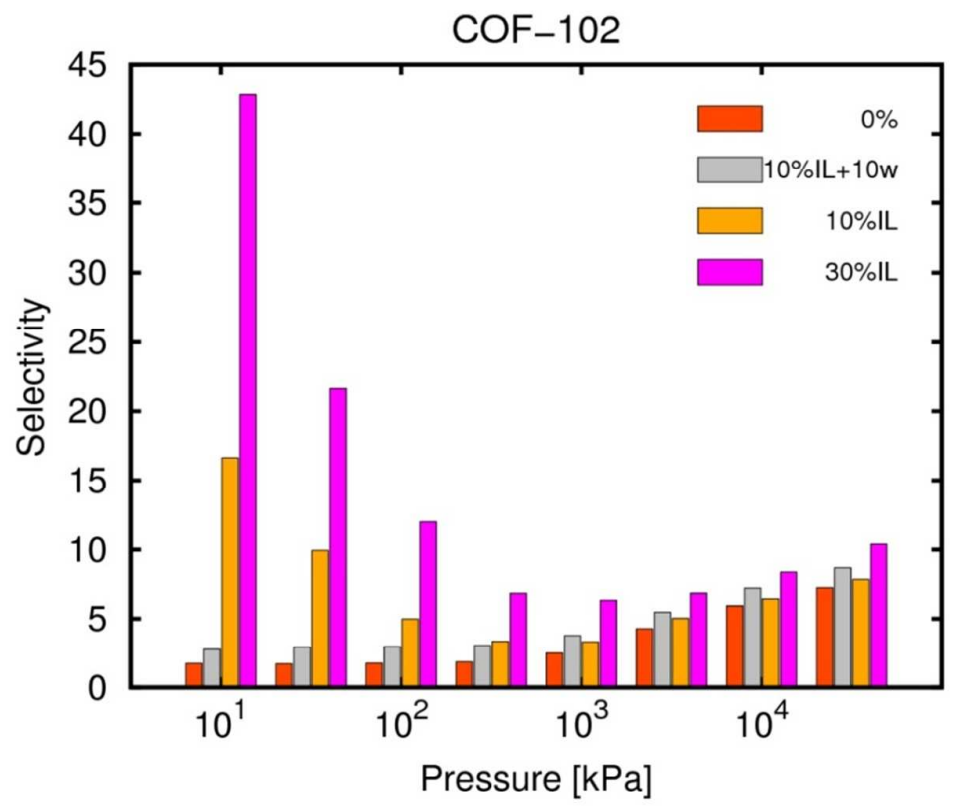

Figure S16. $\mathrm{CO}_{2} / \mathrm{CH}_{4}$ adsorption selectivity calculated from the adsorption isotherm of the equimolar mixture in COF-102 (0\%), COF-102 with IL (10\%-30\%), and in COF102 with $10 \%$ IL and $10 \%$ water.

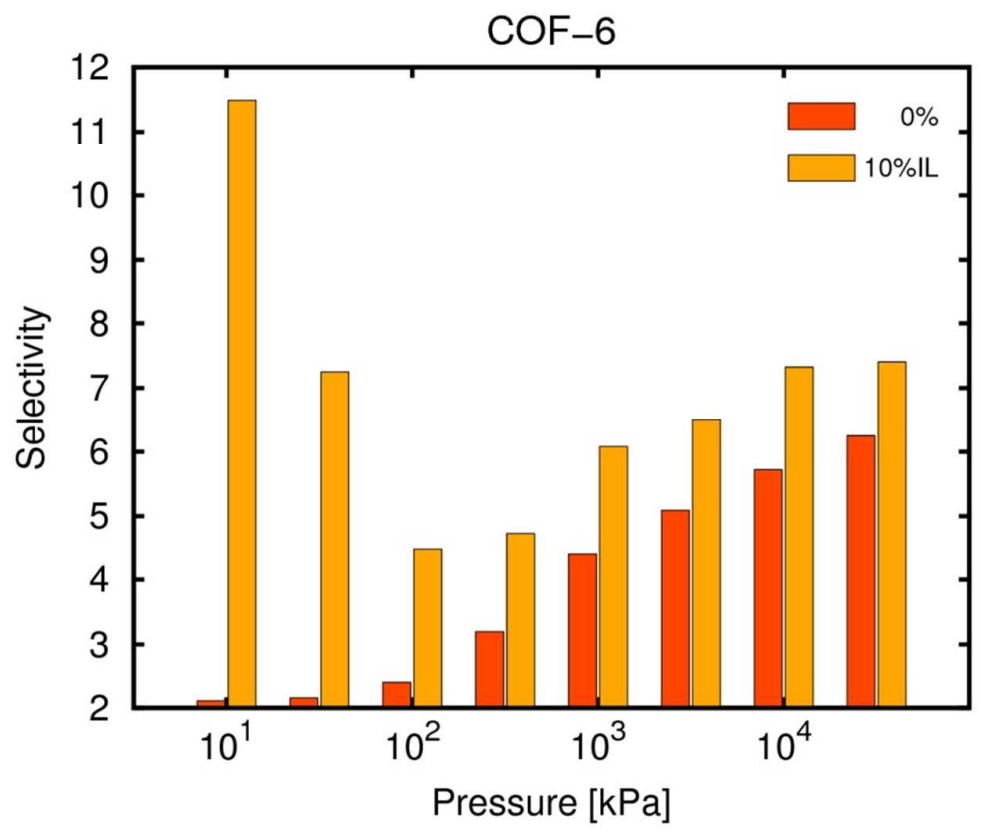

Figure S17. $\mathrm{CO}_{2} / \mathrm{CH}_{4}$ adsorption selectivity calculated from the adsorption isotherm of the equimolar mixture in COF-6 (0\%) and COF-6 with 10\% of IL. 


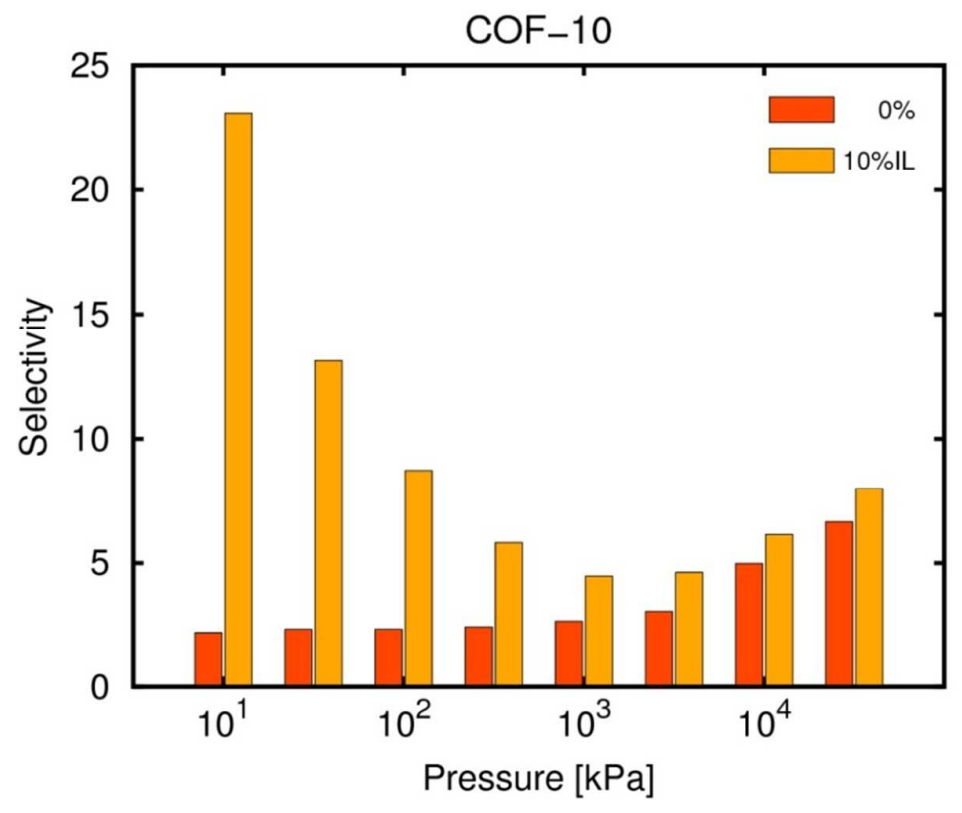

Figure S18. $\mathrm{CO}_{2} / \mathrm{CH}_{4}$ adsorption selectivity calculated from the adsorption isotherm of the equimolar mixture in COF-10 (0\%) and COF-10 with $10 \%$ of IL.

\section{REFERENCES}

(1) Kim, J.; Kim, H. J.; Lim, J. H. Solubility of $\mathrm{CO} 2$ in ionic liquids containing cyanide anions: [c2mim][SCN],[c2mim][N(CN)2],[c2mim][C(CN)3], Fluid Phase Equilib. 2014, 367, 151-158. 